\title{
Ipostaze ale recuperării critice a operei unui scriitor „minor" - Ionel Teodoreanu
}

Drd. PANAITE Claudia-Cristina Universitatea „Dunărea de Jos”, Galați

\begin{abstract}
Ionel Teodoreanu, "the most distinguished writer of his generation", remained under the shadow of the great writers of his time such as Camil Petrescu, Cezar Petrescu, Hortensia Papadat-Bengescu and, he has among them an inglorious and unique destiny. He gets harsh attacks from the great critics of the time and is somehow ignored. Teodoreanu's creation is generating and will continually rise various historical, literary and aesthetic (re)interpretations. Ionel Teodoreanu is an prolific writer who is appreciated only for texts he wrote about childhood, but he also deals with precarious themes such as history through which he enters a socially and historically tough time and, at the same time, he assumes the destiny of his generation. In the article that we are going to present we will analyze the vision of critics in order to reestablish the author, to equalise him with others authors and, also, to place him among canonical writers. This re-establishment will be accomplished through arcadic medelenism, according to Stanomir's and Mitchievici's current critic discourse.
\end{abstract}

Keywords: critic recovery, minor writer, current critic discourse, arcadic medelenism.

Paul Cernat își propune să demonstreze în lucrarea „Modernismul retro în romanul românesc interbelic" faptul că proza romanescă nu trebuie receptată doar din perspectiva teoriilor lovinesciene, întrucât nu se va reuși evidențierea clară a modernității speciei literare amintite. El abordează creații precum „La Medeleni” a lui Ionel Teodoreanu sau unele romane ale lui Mihail Sadoveanu, Cezar Petrescu, Mateiu Caragiale și alții pentru a le oferi o nouă receptare critică, menită să le pună în valoare. Criticul vorbește de un modernism „retro"297, acel liant al scrierilor autorilor menționaţi. Ionel Teodoreanu este printre scriitorii care nu mai sunt la fel de valorizați, el, afirmând criticul, rămânând unul dintre cei mai reprezentativi prozatori ai generației de după unirea din 1918. Nu trebuie să fie considerat doar un simplu scriitor ce așază într-o dimensiune lirică vârste precum copilăria și adolescența, dintr-o perspectivă abundent

297 Paul Cernat, „Modernismul retro în romanul românesc interbelic”, Editura ART, București, 2009, p. 12 
metaforizantă, ci merită să fie perceput ca autor al unui roman exponențial pentru anii `20. Deși cea mai mare parte a criticii literare și-a propus să-1 infiereze, stigmatizându-l, Teodoreanu este modernist din perspectiva sensibilității artistice, situându-se la granița dintre decadentism și expresionism. Astfel, criticul dorește să reabordeze elemente insuficient analizate sau unele dintre ele pierdute din vedere destructurând, demitizând, clișee, prejudecăți, revalorizează opere desconsiderate pe nedrept, încercând să le aducă în locul în care ele meritau să fie, alături de alte creații aflate pe aceeași treaptă din punct de vedere axiologic.

Ionel Teodoreanu este un scriitor reprezentativ pentru revista „Viaţa Românească" a cărui operă surprinde remarcabil o opoziție evidentă între Iași și București, astfel încât acel Iași „patriarhal”298 este grefat în creația prozatorului cu tot ce are el specific, și anume cu locuința bunicilor, $\mathrm{cu}$ imaginea familiei fericite proiectate din perspectiva membrilor acesteia: părinți, frați, dar și cu fresca ținutului Medelenilor: "[...] o Arcadie imaginară, un paradis pierdut al vacanțelor inocente și al frăgezinilor adolescentine, frivol-epicureice. Acest paradis moldav se cere a fi conservat, salvat prin scris, ca o revanșă melancolică, impotriva inevitabilei, apocalipticei dispariții a <<lumii sufletești >, dar și ca o datorie față de sine și față de propriul Trecut" 299 . Teodoreanu percepe, așadar, acel spațiu ca pe un tărâm utopic pe care încearcă să-l recupereze prin intermediul amintirii și să-l fixeze în eternitate prin scriitură. Scriitor destul de controversat, Ionel Teodoreanu reface în textele sale o atmosferă a unei Belle Epoque trecute, remarcându-se printr-un "estetism modernist" $300:$ "Un estetism lasciv-erotizat uneori, crepuscular alteori, în care gidismul cochetează cu simbolismul decadent, iar ecourile din $<<$ clasici $>>$ precum Turgheniev, Jules Renard și din Anatole France- cu cele din <<modernişti > precum Proust, Gide sau Alain Fournier."301

Scriitorul s-a bucurat de succes, dar a fost, în egală măsură, contestat de critici, atât de cei post-maiorescieni, cât și de cei criterioniști sau de avangardiști, după cum subliniază Paul Cernat în lucrarea sa. Lui Teodoreanu i s-au reproșat prelungirile postromantice, precum și cele post-sămănătoriste și postsimboliste, contestându-i-se predilecția pentru latura idilică, pentru dimensiunea paseistă sau preferința pentru vechea lume boierească. De asemenea, au fost surprinse depreciativ abundența metaforelor, inflația lirică, fragilitatea epicului,

\footnotetext{
298 Ibidem, p. 199

${ }^{299}$ Ibidem

300 Ibidem

301 Paul Cernat, op. cit., p. 199
} 
compoziția hibridă sau analiza psihologică nereușită. Adesea, opera sa a fost identificată cu lirismul sentimental, cu senzualitatea de tip kitsch, creația sa emanând o lipsă a maturității literare:,, Un poet în proză deghizat în romancier, desuet ca formulă, de un "talent" flamboaiant și minor, un "Metaforel" prolix, un tenor liric și un seducător ieftin, un autor „popular” și deci persiabil. Un spirit paseist și desuet, inaderent la modernizarea autentică, ba chiar cu regretabile alunecări naționaliste și reacționare." ${ }^{302}$ Astfel, prozatorului i se reproșează aplecarea către liric, având o obsesie a trecutului, devenind astfel reticent față de nou, față de modern. Abundeța metaforei este și ea percepută ca nefirească generând texte prolixe. Critica modernistă l-a stigmatizat în epocă pe Teodoreanu, această stigmatizare prelungindu-se și după anii 60, dar un prim pas pentru recuperarea autenticității scrierilor sale îl face Michel Wattremez prin teza de doctorat "L ' art romanesque de Ionel Teodoreanu dans la Medeleni(19251927)". Cercetătorul își propune să demonstreze maniera în care trilogia lui Ionel Teodoreanu a fost asaltată de o serie de prejudecăți, lecturile critice fiind, astfel, inadecvate, neluând în calcul aspecte relevante ale textelor sale. Opera capitală rămâne „La Medeleni”, roman de "prim-plan” al imaginarului epic interbelic, fiind nu doar o simplă scriere care promovează un univers paseist, ci un adevărat bildungsroman cu aspecte de „metaroman”303: „[...] La Medeleni este o scriere hibridă și- într-un anume sens- monografică, în care utopia idilică a vacanțelor patriarhale se îmbină cu conștiința lucidă a catastrofei inevitabile, și în care feeria vârstelor dintâi alunecă spre apocalipsă, spre a fi apoi $<<$ recuperată $>>$ imaginar de cartea care-ncepe a scrie." $" 304$

Mihai Ralea aprecia, pe bună dreptate, după cum afirmă Paul Cernat, că romanul lui Ionel Teodoreanu este primul roman semntificativ al generației de scriitori care s-a afirmat după prima conflagrație mondială. Prozatorul însuși sublinia într-o notă a ediției princeps faptul că „La Medeleni” se dorește a fi o opera dedicată acelei perioade în care o întreagă generație de moldoveni și-a derulat copilăria, acea vârstă de aur a existenței, între niște repere bine stabilite care se cer recuperate, și anume: căminul patriarhal, valsul demodat sau jazz-

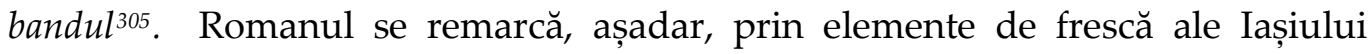
decadent, opera reliefând o gamă de personaje, de la acei liceeni, servitori,

\footnotetext{
302 Ibidem, p. 200

${ }^{303}$ Ibidem, p. 201

304 Ibidem

305 Ibidem
} 
artiști, intelectuali, funcționari, avocați, până la moșieri, boieri, negustori evrei, imbogăţiţii perioadei de după Primul Război Mondial.

Odată ce s-a mutat la București, scriitorul suferă un proces al exilului interior, imaginarul literar racordându-se tot la elementele autobiografice, pe care le valorifică dintr-o perspectivă nostalgică, textele sale țesându-se în jurul imaginii de odinioară a Iașiului: „Mitologia personală se suprapune, aici, cu cea ieșeană în splendide monografii evocatoare, ceremonioase și ludice, cu fond liric și parfum desuet. Prin ele, mai ales, Ionel Teodoreanu recâștigă sufragiile criticii de autoritate." 306 Paul Cernat așază în prim-plan un marginal, Ionel Teodoreanu, care se orientează către București, raportându-se ca la un nou Centru, el își reconfigurează astfel identitatea, forța centripetă îl îndepărtează de Centrul inițial, căre cel actual, el fiind forțat să părăsească universul vechi și să se orienteze către unul nou, modern, în ascensiune.

Ionel Teodoreanu va fi reintrodus în manualele școlare, imediat după acea perioadă interbelică, atât la ciclul primar, cât și la cel gimnazial, dar va fi în continuare stigmatizat, perceput ca un prozator care suprinde în paginile cărților sale copilăria și adolescența, și deși, va reintra în grațiile publicului, nu va câștiga bătălia cu acel canon literar impus de critici. Nicolae Ciobanu, editorul său este cel care va analiza în monografia dedicată scriitorului „natura dublă, cosmopolită, modern și conservator deopotrivă." 307

Mihai Ralea, Grabet Ibrăileanu, Perpessicius, Mircea Eliade sau Camil Petrescu au apreciat romanul "La Medeleni"ca fiind unul spectaculos prezentând elemente de modernitate, atât din punct de vedere compozițional, cât și din punctul de vedere al problematicii abordate, anume cea a „vârstelor dintâi", prozatorul fiind printre primii care ilustrează în creația sa aceste aspecte în imaginarul literar de după conflagrația mondială. Nu de puține ori, textele lui Teodoreanu au fost asemănate cu cele ale scriitorilor occidentali precum Proust, Rolland, Fournier sau Gide. Similitudinile identificate se raportează la coordonatele tematice: „Ele(similitudinile) merg de la trilogia Jean Cristophe a lui Romain Rolland, cu care Medelenii prezintă vizibile similitudini tematice(există chiar trimiteri explicite în text, prin intermediul lui Mircea Balmuş) până la Proust(În căutarea timpului pierdut), Alain Fournier(Cărarea pierdută) și Gide(Fructele pământului, Journal des Faux-Monnayeurs ș. a.), de la „impresionism” la "tolstoism"(Ibrăileanu face inclusiv o trimitere la Ulise de Joyce!), de la Turgheniev la

\footnotetext{
306 Paul Cernat, op. cit., p. 208

307 Ibidem, p. 216
} 
Jules Renard și de la esteți(Oscar Wilde, Paul Bourget, L. Andreev) la expresioniști(Wedekind)."308

Deprecierea operei lui Ionel Teodoreanu s-a realizat în mai multe etape, după cum afirmă criticul Paul Cernat, prima etapă este constituită de receptarea critică pe care o realizează Eugen Lovinescu în „Istoria literaturii române contemporane", însă, în egală măsură, aceeași atitudine va fi perpetuată de către Pompiliu Constantinescu, dar și de către Șerban Cioculescu. G. Călinescu evidențiază doar câteva aspecte pozitive ale scrierilor acestui prozator, și anume: personajele feminine bine individualizate care-și pun amprenta asupra spațiului literar românesc, Olguța și Monica, dar și modalitatea insolită a acestuia de a prezenta copilăria cu inocența ei, cu specificitatea vârstei.

Nicolae Manolescu este cel care atât în "Arca lui Noe”, cât și în „Istoria critică.." apoi îl desființează pe Ionel Teodoreanu, plasându-l definitiv în sfera minoratului: "[...] Eugen Lovinescu acuză<<neosemănătorimul moldovenist $>>$ al autorului din Hotarul nestatornic, G. Călinescu impută <<exagerarea regionalismului inteligent al lui Ibrăileanu>> devenit în La Medeleni <<separatism>> sufletesc între Moldova și Munteania, iar N. Manolescu taxează drastic flatarea gustului burghez al epocii printr-un <<kitsch made in 1930>>." 309 Contestatarii lui Teodoreanu acuză exploatarea lirismului, logoreea protagoniștilor, abundența dialogurilor, haosul, precaritatea firului narativ, prolixitatea. Manolescu atacă romanul „La Medeleni" considerându-l lipsit de autenticitate, analiza psihologică fiind extrem de superficială, pierzându-se în tiparul epic.

Odată cu trecerea timpului Ionel Teodoreanu nu mai este acuzat de afinități semănătoriste prin aplecarea spre trecut sau prin latura lirică a eroilor, ci de "compromie comercial” $310 \mathrm{cu}$ acel gust al burgheziei. Paul Cernat evidențiază, însă, că romanul surprinde, din contră, o ironiei a intregii mentalităţi burgheze, Olguța și Vania se revolt, Dănuț nu se poate adapta, Mircea eșuează, Rodica cunoaște un parcurs lamentabil, iar Puiu este amoral. G. Călinescu îl acuză pe Teodoreanu că ar fi realizat prin operele sale un separatism sufletesc, acest aspect gâsindu-și sorgintea în dorința lui de a unifica din punct de vedere simbolic literatura autohtonă. Paul Cernat condideră că recepatarea critică făcută de G. Călinescu ar comite o eroare ce se bazează pe confuzia dintre alter ego și viziunea autorului: ", Tot încercând să ne convingă de neverosimilul vieții de licean în București pe care o duce Dănuț de parcă liceenii din Cartea nunții ar fi mult mai

\footnotetext{
308 Ibidem, p.218

309 Paul Cernat, op. cit., p 219

310 Ibidem, p. 223
} 
versomili...), Călinescu uită că și Olguța poate fi privită ca alter ego al autorului, iar perspective acestei moldovence dinamice asupra Bucureștiului și a Munteniei este, cum am văzut, entuziastă." 311 . La Medeleni este o creație care denotă putere reușind să transceandă canoanele romanești ale vremii: „Și totuși în pofida tuturor obiecțiilor!), La Medeleni impune prin forța cu care, spărgând tiparele romanești convenționale, reușește să învie o lume și o atmosferă, printr-o obiectivare foarte...subiectivă, $<<$ panlirică $>>>^{\prime 312}$. Astfel, privind cu atenție aspecte care pot părea dezordonate, anarhice, inutile, se validează din perpectiva unui imaginar evoluat din perspectivă estetică.

Paul Cernat identifică un tip nou de mimesis în creația lui Teodoreanu, având în vedere și mărturisirile autorului în epocă: "Avem de-a face cu un nou tip de mimesis și de autenticitate în redarea atmosferei copilărești sau adolscente, un mimesis care nu mai operează prin distanțarea $<<$ obiectivă $>>$ a perspectivei auctoriale față de personaje, ci prin identificarea cu modul de a vorbi, de a gândi și simți al acestora; nu prin anamneză, ci printr-un soi de regresie deliberată la nivelul mentalului copilăriei și al adolescenței." ${ }^{1313}$ Criticul surprinde originalitate cu care cele două vârste sunt prezentate, realizându-se o regresie în mentalul lor, dar și o identificare cu modul de a comunica, de a raționa sau de a simți al eroilor.

Critica românească postbelică nu oferă decât un singur critic semnificativ care așază în prim-plan latura inovativă autentică a operei lui Ionel Teodoreanu, iar acesta este Mihai Zamfir. El consideră că abundența metaforelor denotă esența artei scriitorului. Prozatorul metamorfozează liricul, țesând astfel o structură epică. Așadar, creația lui Teodoreanu va inova ceea ce romanul în general va demonstra, proustianismul fiind mai evident în prozele sale decât s-ar fi crezut inițial. Sciitorul nu se poate identifica cu ai săi eroi structura polifonică a textelor sale ferindu-l de acest aspect: „Sunt puțin prozatorii români interbelici capabili să-și audă și individualizeze, în asemenea măsură, personajele prin limbajul lor(dar și prin lecturile lor). S-ar zice că Ionel Teodoreanu- care nu a scris teatru, deși a fost o vreme director al Teatrului Național din Iași- a asimilat, în roman, lecția teatrului satiric și a oralităților[...]"314. Scriitorul își individualizează personajele prin limbaj, prin lectură, asimilând în proză elemente ale experienței sale teatrale.

\footnotetext{
${ }^{311}$ Ibidem, p. 224

312 Ibidem, p. 227

${ }^{313}$ Ibidem, p.228

314 Paul Cernat, op. cit, p. 230
} 
Paul Cernat contracarează acuzele lansate de către Mihai Ralea referitoare la o literaturizare abundentă, inserții în exces a elementelor livrești în opera lui Teodoreanu, găsind aceste reproșuri inadecvate. El vede în textul lui Ionel Teodoreanu un metaroman autentic și nu parazitar, defectuos, ca ceilalți critici:, La Medeleni este, esențial, un roman de formare și de inițiere a scriitorului Dan Deleanu întru medelenism, Lumea prezentată trebuie, spre a supraviețui, să sfârșească într-o carte. Sau dintr-o perspectivă textualizantă, să acceadă la propria Scriitură și propriul text." ${ }^{315}$ Deși de cea mai mare parte a criticii a fost perceput ca un bildungsroman incomplet, "La Medeleni” este după cum demonstrează exegetul M. Wattremez o scriere inițiatică ce prezintă asemănări cu textele lu Gide sau Huxley, Eliade sau Petrescu, amintind, de asemenea, de noul roman francez în direcția imprimată de Nathalie Sarraute.

Paul Cernat identifică un tip nou de mimesis în creația lui Teodoreanu, având în vedere și mărturisirile autorului în epocă: „A Avem de-a face cu un nou tip de mimesis și de autenticitate în redarea atmosferei copilărești sau adolscente, un mimesis care nu mai operează prin distanțarea <<obiectivă >> a perspectivei auctoriale față de personaje, ci prin identificarea cu modul de a vorbi, de a gândi și simți al acestora; nu prin anamneză, ci printr-un soi de regresie deliberată la nivelul mentalului copilăriei și al adolescenței." Criticul surprinde originalitate cu care cele două vârste sunt prezentate, realizându-se o regresie în mentalul lor, dar și o identificare cu modul de a comunica, de a raționa sau de a simți al eroilor.

Critica românească postbelică nu oferă decât un singur critic semnificativ care așază în prim-plan latura inovativă autentică a operei lui Ionel Teodoreanu, iar acesta este Mihai Zamfir. El consideră că abundența metaforelor denotă esența artei scriitorului. Prozatorul metamorfozează liricul, țesând astfel o structură epică. Așadar, creația lui Teodoreanu va inova ceea ce romanul în general va demonstra, proustianismul fiind mai evident în prozele sale decât s-ar fi crezut inițial. Sciitorul nu se poate identifica cu ai săi eroi structura polifonică a textelor sale ferindu-l de acest aspect: "Sunt puțin prozatorii români interbelici capabili să-și audă și individualizeze, în asemenea măsură, personajele prin limbajul lor(dar și prin lecturile lor). S-ar zice că Ionel Teodoreanucare nu a scris teatru, deși a fost o vreme director al Teatrului Național din Iași- a asimilat, în roman, lecția teatrului satiric și a oralităților[...]" . Scriitorul își individualizează personajele prin limbaj, prin lectură, asimilând în proză elemente ale experienței sale teatrale.

\footnotetext{
315 Ibidem, p. 232
} 


\section{Bibliografie}

Călinescu, George, Istoria literaturii române de la origini până în prezent, Ed. Semne, 2003;

Cernat, Paul, Modernismul retro in romanul romanesc interbelic, Ed. Art, București, 2009;

Ciobanu, Nicolae, Ionel Teodoreanu - viața și opera, Ed. Minerva, București, 1970. 